\title{
Expression of intercellular adhesion molecule-1 (ICAM-1) and vascular cell adhesion molecule-1 (VCAM-1) on proliferating vascular endothelial cells in diabetic epiretinal membranes
}

\author{
Shibo Tang, Kim Chi Le-Ruppert, Veit-Peter Gabel
}

\begin{abstract}
The present study demonstrated the expression of intercellular adhesion molecule-1 (ICAM-1) and vascular cell adhesion molecule-1 (VCAM-1), the proliferating status of the neovascular endothelial cells, and the activation of vascular endothelial cells bearing the two cell adhesion molecules in diabetic epiretinal membranes by using double immunofluorescence and APAAP techniques. The results showed that ICAM-1 was detected in 36 out of $40(90 \%)$ proliferative diabetic retinopathy epiretinal membranes, VCAM-1 was found in 32 out of 40 cases (80\%); in 21 out of $26(81 \%)$ vascularised membranes the endothelial cells of the new vessels in the membranes were still in a proliferative stage (positive for proliferating endothelial cell marker EN 7/44) and, further, in 20 out of 26 cases $(77 \%)$ ICAM-1 was detected on the proliferating endothelial cells and VCAM-1 was found in 21 cases $(81 \%)$. The expression of cell adhesion molecules, especially ICAM-1 and VCAM-1 in diabetic epiretinal membranes suggests that cell to cell interactions may play a significant role in the development of PDR membranes. In particular, the expression of ICAM-1 and VCAM-1 on proliferating endothelial cells indicates the activation of these cells, which is the first critical step for lymphocyte/endothelial cell interactions and the initiation of immune responses. The significance of proliferating status of the neovascularisation in the membranes may be related to the clinical course and prognosis of the disease.
\end{abstract}

(Brf Ophthalmol 1994; 78: 370-376)

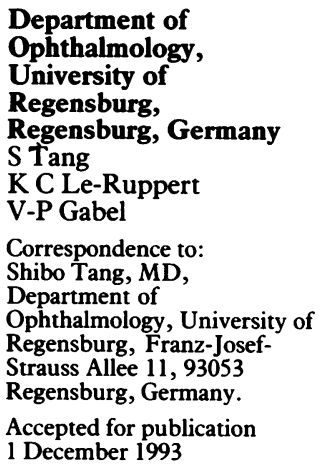

Diabetic epiretinal membranes are the main pathological changes of proliferative diabetic retinopathy (PDR) which may cause severe complications resulting in blindness. The mechanism of the development of diabetic epiretinal membranes is still unknown. Studies of histopathology and immunohistochemistry demonstrated that these membranes consist of different types of cells such as fibroblasts, glial cells, retinal pigment epithelial cells, and macrophages, and different types of extracellular matrixes. ${ }^{1-6}$ On the other hand, some other studies demonstrated the presence of immune cells, immunoglobulins, and complement proteins in the epiretinal membranes implicating the involvement of the immune system. ${ }^{7-9}$ The participating cells seem to grow in concert, mutually influencing tissue proliferation. ${ }^{10}$ In multicellular tissues such as epiretinal membranes cell-cell interactions may be a major factor in the control of cell migration, cell recognition and adhesion, cell differentiation, and proliferation. Intercellular adhesion molecule-1 (ICAM-1) and vascular cell adhesion molecule-1 (VCAM-1) are two of the cell adhesion molecules (CAMs) which are considered to be important for the initiation of some adhesion dependent immune responses. ${ }^{11}{ }^{12}$ ICAM-1 and VCAM-1 have been known to participate in the process of lymphocyte adherence to the vascular endothelial cells, which is important for the entry of lymphocytes into the sites of immune responses or inflammation. ${ }^{1314}$

Histopathological studies have also shown that the new vessels are one of the components of the epiretinal membranes of PDR. ${ }^{23}$ Most of the new vessels, some of which are fenestrated, in epiretinal membranes are associated with a thickened, multilaminated basement membrane. ${ }^{315}$ Although immunohistochemical studies have shown the expression of MHC class II antigens on the vascular endothelial cells and the deposits of immunoglobulins and complement factors in the vascular wall, ${ }^{8}$ the proliferative activity and the activation of the vascular endothelial cells in diabetic epiretinal membranes have not yet been studied in detail. In the present study, we investigated, using immunohistochemical techniques, the extent of the neovascularisation with a monoclonal antibody against proliferating vascular endothelial cells and the expression of the intercellular adhesion molecule-1 (ICAM-1) and the vascular cell adhesion molecule-1 (VCAM-1) which are two of the markers for endothelium activation in diabetic epiretinal membranes.

\section{Materials and methods}

COLLECTION AND PROCESSING OF EPIRETINAL MEMBRANES

In this study, a total of 40 diabetic epiretinal 
membranes were studied. They were surgically excised from 40 patients with proliferative diabetic retinopathy during pars plana vitrectomy. All except one case had undergone panretinal argon laser photocoagulation before vitrectomy. The epiretinal membranes (as much as possible) were carefully peeled off the retinal surface, excised with microscissors and taken out of the vitreous cavity by a microforceps. Immediately after excision, the membrane specimens were placed in Ringer's solution or balanced salt solution (BSS) and maintained at $4^{\circ} \mathrm{C}$. They were then embedded in OCT (Tissue-tek) compound and snap frozen in isopentane (2-methylbutane) chilled previously with liquid nitrogen. Cryosections $(6 \mu \mathrm{m})$ were cut and mounted on $0 \cdot 1 \%$ poly- $l$-lysin precoated slides and air dried at room temperature for 4 hours. The slides were then fixed in cold acetone for 10 minutes and wrapped, stored at $-40^{\circ} \mathrm{C}$ until use.

After their use for the immunohistochemical study, the rest of the specimens were fixed in $10 \%$ formaldehyde solution for 6 to 24 hours. They were then processed for routine haematoxylin and eosin staining for the assessment of cellularity and cell morphology.

\section{MONOCLONAL ANTIBODIES}

A mouse monoclonal anti-human proliferating endothelial cell antibody EN 7/44 (Dianova, Germany) was used to evaluate the extent of the neovascularisation in the membranes. EN 7/44 is a mouse IgM recognising a $30 \mathrm{kDa}$ glycoprotein on the surface of the proliferating or inflamed vascular endothelial cells, but not the normal or mature endothelial cells. ${ }^{17}$ The working dilution of this antibody was 1:100 in TRIS/ $\mathrm{HCl}, \mathrm{pH} 7 \cdot 6$.

For detecting the activation situation of vascular endothelial cells and the expression of cell adhesion molecules in the epiretinal membranes, two mouse monoclonal antibodies against human CAMs, anti-ICAM-1 and anti-VCAM-1, were used. Anti-ICAM-1 (clone 84H10, Dianova, Germany) is a mouse IgGl which recognises CD54 antigen on a variety of types of cells, such as on monocytes/macrophages, on activated lymphocytes, and on activated vascular endothelial cells and fibroblasts. ${ }^{18-20}$ The working dilution of this antibody was $1: 250$ in TRIS/HCl, pH 7·6. Anti-VCAM-1 (clone 1G11, Dianova, Germany) is also a mouse IgGl that recognises VCAM-1, a $90 \mathrm{kDa}$ membrane glycoprotein present on activated vascular endothelial cells. ${ }^{21}$ Its working dilution was $1: 100$ in TRIS/ $\mathrm{HCl}$, pH 7·6.

The working dilutions mentioned above of all antibodies used were respectively optimised by testing and comparing different dilutions of the antibody in the stain.

DOUBLE STAINING PROCEDURE

To demonstrate the expression of the two CAMs, ICAM-1 and VCAM-1, on the proliferating vascular endothelial cells, a double immunofluorescence procedure was performed. The frozen sections were first placed in phosphate buffered saline (PBS) (pH 7.4) buffer bath for 5 minutes, then incubated with the first primary antibody EN 7/44 in a humid chamber at room temperature for 45 minutes. Following a wash with PBS, the second primary antibody, antiICAM-1 or anti-VCAM-1, was added to the slides and incubated for 45 minutes under the same conditions as above. The slides were rinsed gently several times. They were then incubated with a fluorescein isothiocyanate derivative (DTAF) conjugated goat anti-mouse IgM antibody (1:200, Dianova, Germany) for 30 minutes. After rinsing again, the slides were incubated with the second chromophore, cyanine isothiocyanate (Cy3) conjugated goat anti-mouse IgG antibody (1:200, Dianova, Germany) for another 30 minutes. The slides were then washed in PBS for about 5 minutes, mounted with glycerol gelatine, and observed under a fluorescence microscope with a wavelength of $492 \mathrm{~nm}$ for DTAF and a wavelength of $553 \mathrm{~nm}$ for Cy3. Photographs were taken simultaneously.

\section{ALKALINE PHOSPHATASE ANTI-ALKALINE}

PHOSPHATASE (APAAP) TECHNIQUE

In parallel with immunofluorescence procedure, APAAP staining procedure was also performed in order to ensure and confirm the results obtained. Briefly, the slides were rehydrated in $0.05 \mathrm{M}$ TRIS/ $\mathrm{HCl}$ ( $\mathrm{pH} \mathrm{7.6)}$ for 2-3 minutes, then incubated with normal rabbit serum or IgG for 15 minutes to block and avoid non-specific staining. After removing the fluid gently (without rinsing), they were incubated with the primary monoclonal antibodies in a humid chamber at room temperature for 45 minutes. The slides were rinsed gently. They were then incubated with the link antibody (rabbit antimouse IgG, Dako, Germany) under the same conditions for 30 minutes. After rinsing again, they were incubated with the APAAP complex (mouse IgG coupled with alkaline phosphatase, Dako, Germany) for 30 minutes. In order to amplify the staining signal, the procedures of link antibody incubation and APAAP complex incubation were repeated. Then, $0 \cdot 1 \%$ fast red substrate (containing naphthol phosphate, 4-chloro-2-methylbenzendiazonium and levamisole) was applied to the slides for 20 minutes. After further rinsing, the sections were counterstained with Mayer's haematoxylin. Following a wash in running tap water for about 5 minutes, they were mounted with glycerol gelatine and observed under a light microscope.

As positive controls, fresh human tonsil tissues from tonsillectomies (offered by the NET Clinic of the University of Munich, Germany) and human rejected kidney tissues after kidney transplantation (offered by the Institute of Immunology, University of Munich, Germany) were tested with the same monoclonal antibodies by using the same techniques described above. Normal posterior tissues of human donor eyes used for keratoplasty and epiretinal membrane specimens tested without the addition of the primary antibodies were used as negative controls.

The stainings for ICAM-1, VCAM-1, and vascular endothelial cells were simultaneously 
performed with the same procedures. In each specimen the cellularity, cell morphology, and the percentage of positively stained cells and vessels were assessed. To assess the degree of cellularity, we counted the number of all cells in three selected views under a microscope (magnification $\times 600$ ). Then an average cell number was calculated and divided into four grades: grade $+(<10$ cells/view $)$, grade $++(10-30$ cells/view $)$, grade $+++(30-50$ cells/view $)$, grade ++++ ( $>50$ cells/view). For evaluation of the density of ICAM-1 and VCAM-1 positive cells, all cells, both positive and negative (also in three selected views under a microscope, $\times 600$ ) were counted and an average positive percentage was calculated.
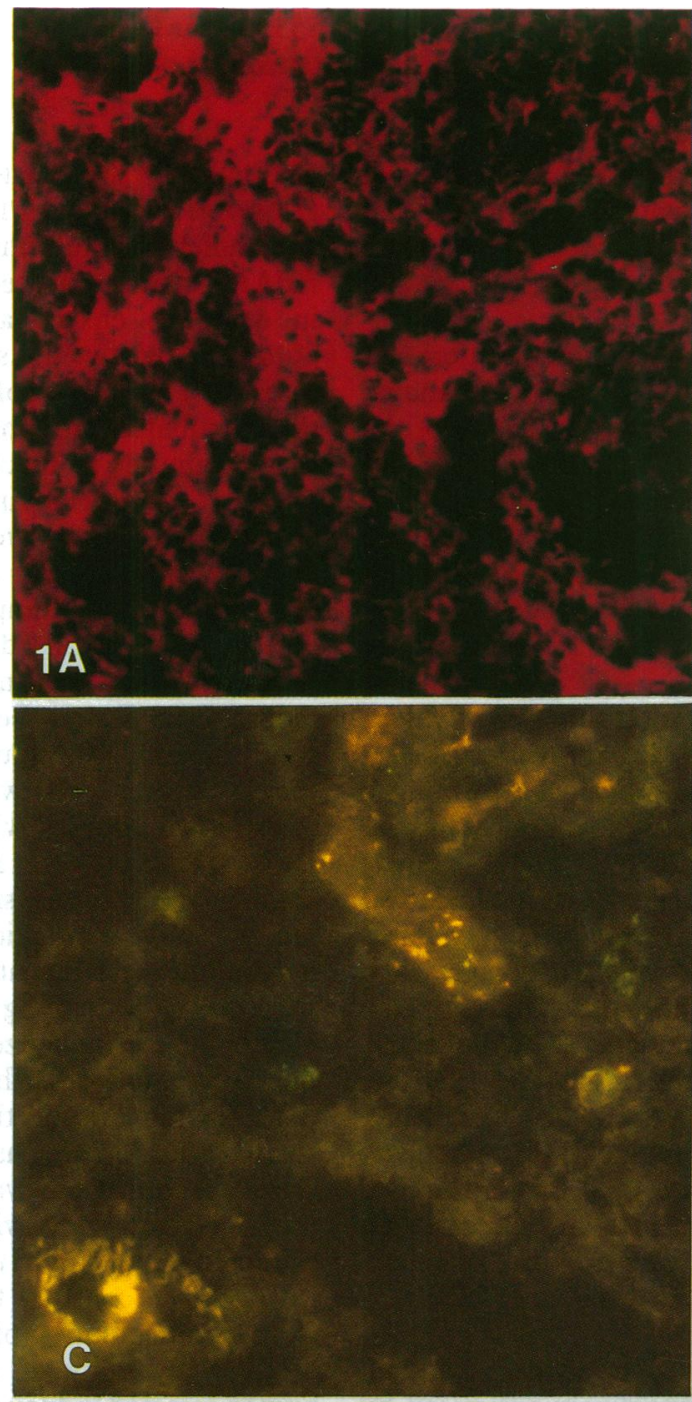

Figure 1 Positive controls. (A) Positive stainings for ICAM-1 in tonsil tissues (immunofluorescence, Cy3, $\lambda=553 \mathrm{~nm}$, magnification $\times 215$ ). (B) Positive staining for VCAM-1 on stromal cells (upper) and in the vessels (lower) of tonsil tissues with tonsillitis (APAAP, Fast red, $\times 345$ ). (C) Positive staining of EN 7/44 in the vessels in human rejected kidney tissues. (D) Positive staining for ICAM-1 in the vessels positive for EN 7/44 (C) and also in tissue stroma of human rejected kidney tissues $(C, D$ : double immunofluorescence, $C: D T A F, \lambda=492 \mathrm{~nm}$, $D: C y 3, \lambda=553 \mathrm{~nm}$, $\times 215)$. $(E, F)$ Positive staining of anti-VCAM-1 $(F)$ in a vessel which was also positive for $E N 7 / 44$ $(E)$ in human rejected kidney tissues (double immunofluorescence, $E: D T A F, \lambda=492 \mathrm{~nm}$, $F: C y 3, \lambda=553 \mathrm{~nm}$, $\times 260$ ).

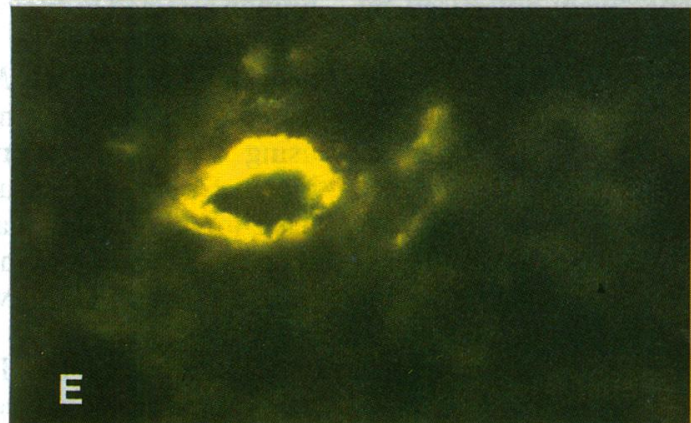

\section{Results}

POSITIVE AND NEGATIVE CONTROLS

The positive controls showed positive immunostaining for all monoclonal antibodies used. ICAM-1 and VCAM-1 were strongly expressed in tonsil tissues and also modestly expressed in rejected kidney tissues. The positive stainings were bright reddish, while the background was clear (colourless) (Figs $1 \mathrm{~A}, \mathrm{~B})$. The cell nuclei were counterstained in blue. Unfortunately, many of them were lost during processing. The proliferation marker was detected by EN 7/44 on the vascular endothelial cells in part of the vessels in both tonsil tissue and rejected kidney tissue in green (immunofluorescence). ICAM-1 and
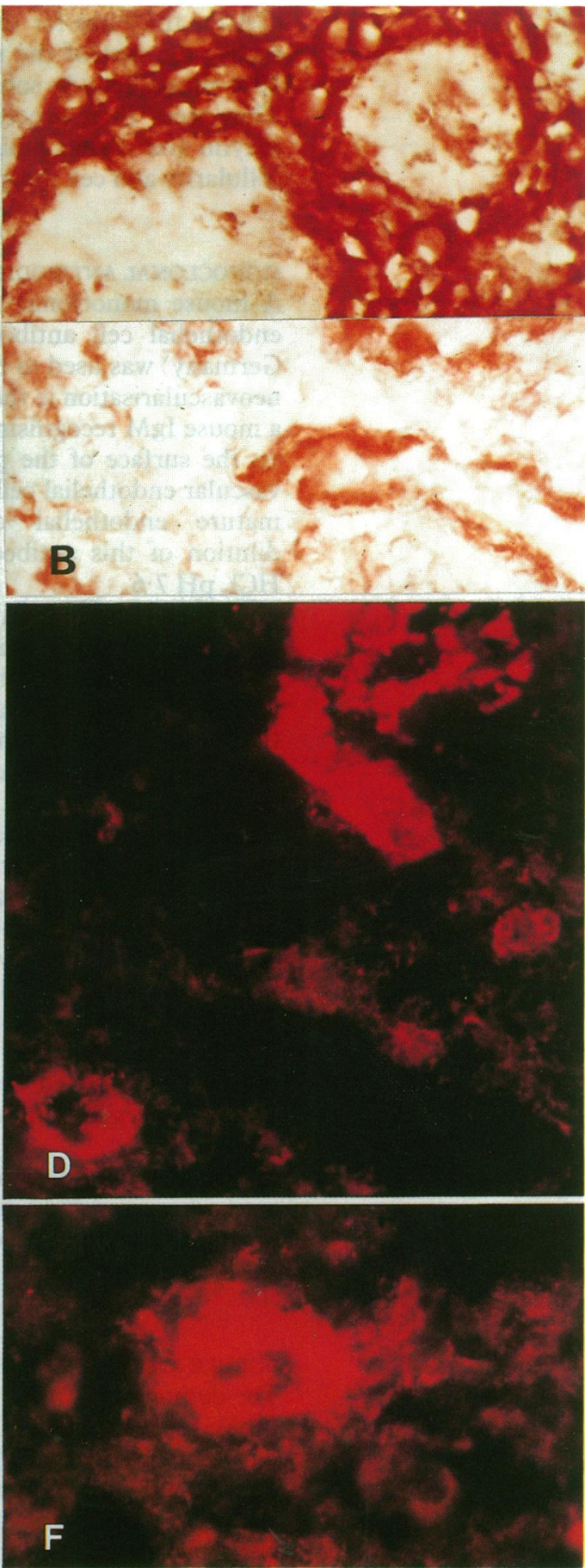
Figure 2 Negative controls. (A) No positive reactions in normal eye tissue (retina, RPE cells, choroidal, and sclera tissues) (APAAP, Fast red $\times 215)$. (B) Negative reactions in epiretinal membrane tissues tested without the primary antibodies (upper: APAAP, Fast red, $\times 135$ lower: immunofluorescence, $\times 135)$.

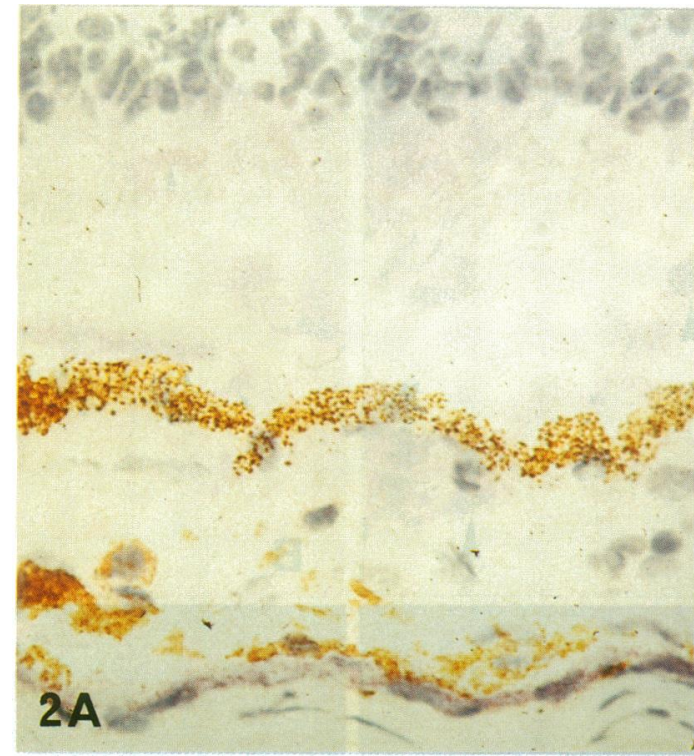

Table 1 Expression of ICAM-1 and VCAM-1 and the status of neovascularisation in diabetic epiretinal membranes

\begin{tabular}{lll}
\hline & $\begin{array}{l}P D R \text { membranes } \\
(n=40)\end{array}$ & $\begin{array}{l}\% \\
\text { stained }\end{array}$ \\
\hline ICAM-1 positive & 36 & 90 \\
VCAM-1 positive & 32 & 80 \\
NV & 26 & 65 \\
P for EN 7/44 & $21 / 26$ & 81 \\
P for EN 7/44+anti- & $20 / 26$ & 77 \\
$\quad$ ICAM-1 & $21 / 26$ & 81 \\
P for EN 7/44+anti- & VCAM-1 & \\
\hline
\end{tabular}

$\mathrm{NV}=$ neovascularisation $; \mathrm{P}=$ positive $\mathrm{PDR}=$ proliferative diabetic retinopathy.

VCAM-1 were also detected on the endothelial cells which were positive for EN 7/44 (Figs 1 C, $D$, and $E, F)$. The positive stainings verified the activity of the primary antibodies used. No positive reactions were found in the negative controls indicating that there was no non-specific reaction (Figs $2 \mathrm{~A}, \mathrm{~B}$ ). The results obtained from immunofluorescence procedures are well correlated with that from the APAAP technique. The staining intensity with both techniques was also similar.

\section{EXPRESSION OF ICAM-1 AND VCAM-1 IN PDR} EPIRETINAL MEMBRANES

In PDR epiretinal membranes, 36 out of 40 specimens $(90 \%)$ were positively stained by monoclonal anti-ICAM-1 antibody, while 32 $(80 \%)$ cases were positive for monoclonal antiVCAM-1 antibody (Table 1). Table 2 shows the density of ICAM-1 and VCAM-1 positive cells in the membranes. This evaluation was possible in 31 cases. ICAM-1 and VCAM-1 were found to be expressed traversing the epiretinal membranes according to the staining on serial sections. The expression of these two molecules was dominantly cell associated in cell populated areas. In many cases they were expressed on the surface (margin) of the membranes. The pattern of staining was similar for both ICAM-1 and VCAM-1. The positively stained cells were mainly small and round (lymphocytes), but sometimes could also be spindle-shaped cells (fibroblasts?), and occasionally even pigmented

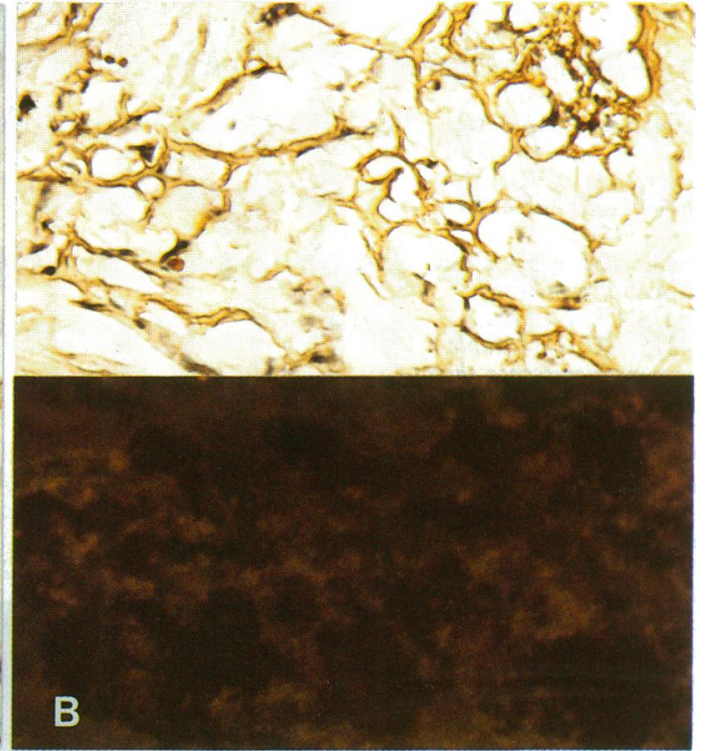

cells (retinal pigment epithelial cells or phagocytic macrophages) (Figs $3 \mathrm{~A}, \mathrm{~B}$ ). In some cases, ICAM-1 and VCAM-1 were distributed diffusely in the intercellular spaces. The intensity of ICAM-1 and VCAM-1 expression varied from case to case and seemed to be correlated with the severity of pathological changes (epiretinal membrane formation) of PDR, but not with the age and sex of the patients. Generally, the expression of ICAM-1 in the membrane tissues was stronger than that of VCAM-1. In addition, ICAM-1 and VCAM-1 were also expressed on the endothelial cells of the vessels in the membranes (see below). Histologically, the membranes positive for ICAM-1 and VCAM-1 were relatively rich in cells and new vessels. Conversely, the membrane specimens (four cases) negative for both ICAM-1 and VCAM-1 were rather thin, had less cellular components, and had fewer neovascularisations. The cellularity of the epiretinal membranes tested and a correlation with ICAM-1 and VCAM-1 expression are shown in Table 3.

\section{NEOVASCULARISATION IN PDR EPIRETINAL}

MEMBRANES

In the present study, 26 out of 40 epiretinal membrane specimens (65\%) contained new vessels. The neovascularisation in membranes was positively stained by EN 7/44 in 21 out of 26 cases ( $81 \%)$. In 20 out of 26 cases (77\%), ICAM-1 was found on proliferating vascular endothelial cells which were positive for EN 7/44 (Figs $3 \mathrm{C}$, D). VCAM-1 was detected on the endothelial cells in 21 out of 26 cases ( $81 \%$ ) which were also

Table 3 Degree of cellularity of the epiretinal membranes and a correlation with ICAM-1 and VCAM-1 expressions

\begin{tabular}{llccc}
\hline & \multicolumn{5}{c}{$\begin{array}{l}P D R \\
\text { membranes } \\
(n=40)\end{array}$} & ICAM-1 & VCAM-I \\
Cells/view & Grades & VA & & \\
\hline$<10$ & + & 5 & 16 & 14 \\
$10-30$ & ++ & 17 & 14 & 11 \\
$31-50$ & +++ & 14 & 4 & 4 \\
$>50$ & ++++ & 4 &
\end{tabular}

$\star$ Magnification $\times 600$. 
Figure 3 Expression of ICAM-1 and VCAM-1. (A) Expression of ICAM-I in PDR epiretinal membranes. (APAAP, Fast red, $\times 345)$. (B) Expression of VCAM-1 on stromal cells and at the levels of vascular endothelial cells in PDR epiretinal membranes APAAP Fast red $\times 215) .(C, D)$ Double immunofluorescence shows the positive staining on vascular endothelial cells for EN 7/44 (C) and for antiICAM-I (D) in diabetic epiretinal membranes. (C: $D T A F, \lambda=492 \mathrm{~nm}, D$ : Cy3, $\lambda=553 \mathrm{~nm}, \times 85)$. $(E$, F) Double

immunofluorescence shows the positive staining on vascular endothelial cells for $E N 7 / 44(E)$ and for anti$V C A M-I(F)$ in diabetic epiretinal membranes. $(E$ : $D T A F, \lambda=492 \mathrm{~nm}, \mathrm{~F}$ : Cy3, $\lambda=553 \mathrm{~nm}, \times 575$ ).

Table 4 Percentage of anti-ICAM-1/antiVCAM-1 positively stained vessels (sections) in total number of

neovascularisations within an epiretinal membrane

\begin{tabular}{ll}
\hline $\begin{array}{l}\text { Positive } \\
\text { vessels }\end{array}$ & $\begin{array}{l}P D R \\
\text { membranes } \\
(n=23)\end{array}$ \\
\hline$<10 \%$ & 2 \\
$10-30 \%$ & 9 \\
$31-50 \%$ & 8 \\
$>50 \%$ & 4 \\
\hline
\end{tabular}
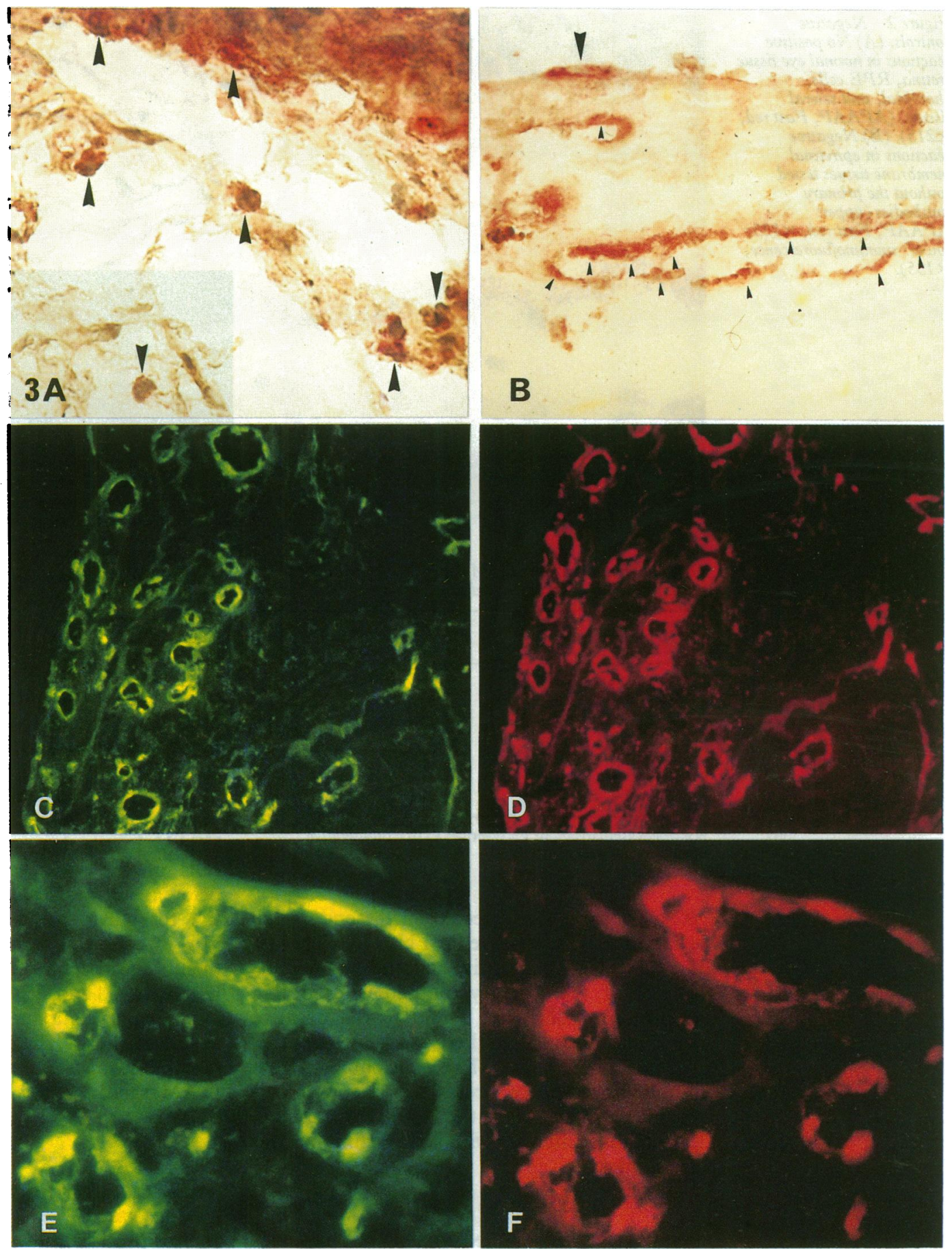

positive for EN 7/44 (Figs $3 \mathrm{E}, \mathrm{F}$ ) (see Table 1). This indicates that most of the vascular endothelial cells in the proliferating stage were also in an activated state. In the positive specimens, only parts of the vessels were positively stained, while others were negative. This indicated that the positively stained new vessels (positive for EN 7/44) were still in the proliferation stage by the time of operation, while some others (negative for EN 7/44) were in a stationary or mature stage. Table 4 shows the percentage of antiICAM-1 or anti-VCAM-1 positively stained vessels (sections) in the total number of neovascularisations within an epiretinal membrane of PDR. In addition, we found that in three cases the vascular endothelial cells expressed VCAM-1, but not ICAM-1. In contrast, in two cases the endothelial cells expressed ICAM-1 but not VCAM-1. Histologically, the three cases positive for VCAM-1 contained more new vessels than the two cases which were only positive for ICAM-1. The five cases negative for EN 7/44 showed more fibrous and fewer vascular components.

\section{Discussion}

The development of proliferative diabetic retinopathy is a very complicated process involving many factors including different types of growth factors, ${ }^{22-24}$ genetic predisposition, ${ }^{25}$ and also autoimmune responses. ${ }^{72627}$ In previous studies we have demonstrated the involvement of cells of the immune system such as macrophages, $T$ helper/inducer, $\mathrm{T}$ suppressor/cytotoxic, and B lymphocytes and some of their cytokines (IL-1 
and IL-2) in diabetic epiretinal membranes. ${ }^{72}$ In order to elucidate the communications and interactions among the immune cells and the interactions between immune cells and vascular endothelial cells in the epiretinal membranes of PDR, in the present study we have investigated the expression of intercellular adhesion molecule-1 (ICAM-1) and vascular cell adhesion molecule-1 (VCAM-1) in 40 PDR epiretinal membranes and on the vascular endothelial cells in these membranes. The results show that ICAM-1 was expressed in $90 \%$ of the specimens tested and VCAM-1 was found in $80 \%$ of the membranes. Neovascularisation was found in $65 \%$ of the membranes in this study. Among them about $80 \%$ were still in the proliferating stage revealed by the staining with EN 7/44 and were activated, which was implicated by the expression of ICAM-1 and VCAM-1 on their endothelial cells. These findings provide further evidence for the initiation of immune responses or inflammatory reactions in diabetic epiretinal membranes.

Intercellular adhesion molecule- 1 and vascular cell adhesion molecule- 1 are members of the immunoglobulin supergene family involved in $T$ lymphocyte-vascular endothelial cell interactions. They serve respectively as endothelial cell surface ligands for the lymphocyte functional antigen-1 (LFA-1) and very late antigen-4 (VLA-4) integrins present on the surface of lymphocytes. The interactions among ICAM-1/ LFA-1 and VCAM-1/VLA-4 result in T cell adhesion to activated vascular endothelium. ${ }^{132}$ For initiation of immune responses lymphocyte migration into tissues is critically important. The interaction of lymphocytes with endothelial cells lining blood vessel walls represents the first critical step in lymphocyte migration into tissues. ICAM-1 and VCAM-1, as counter receptors for lymphocyte LFA-1 and VLA-4, provide dynamic position specific information to guide lymphocyte localisation at the site of immune responses. It has also been shown that the interactions between antigen presenting cells (macrophages/monocytes, etc) and lymphocytes need the involvement of ICAM-1 to generate immune responses and later on the interactions of $\mathrm{T}$ cell to $\mathrm{T}$ cell and also $\mathrm{T}$ cell to $\mathrm{B}$ cell. ${ }^{11}{ }^{12} 30$

In the normal situation, ICAM-1 can be expressed on both haematopoietic cells such as macrophages/monocytes, activated $\mathrm{T}$ lymphocytes, and germinal centre dendritic cells in tonsils and lymph nodes, and non-haematopoietic cells such as vascular endothelial cells, thymic epithelial cells, and fibroblasts. However, the basal expression on non-haematopoietic cells is low. ${ }^{19}$ ICAM-1 is very weakly expressed on resting endothelial cells, but it can be rapidly and markedly increased by the activation of endothelial cells. ${ }^{132931}$ Furthermore, the expression of ICAM-1 can also be induced and increased by some types of cytokines such as interleukin 1 (IL-1), interferon gamma (INF- $\gamma$ ) and tumour necrosis factor beta (TNF- $\beta$ ) on different types of cells - for example, unstimulated cultured retinal pigment epithelial (RPE) cells, fibroblasts, and retinal capillary endothelial cells express low levels or do not express ICAM-1, whereas after the stimulation with above inflam- matory cytokines RPE cells and retinal vascular endothelial cells express high levels of ICAM-1. ${ }^{1932} 33$ In the present study, we could find strong expression of ICAM-1 and VCAM-1 on these cells, which indicates the stimulation or activation of these cells, though they were present in relatively small numbers in the epiretinal membranes observed (Table 2). In this stage they could be as antigen presenting cells playing a role in the initiation of immune responses. Abnormal expression of ICAM-1 has been demonstrated in some disease conditions, such as some immune related diseases of the skin, ${ }^{34}$ and renal allograft rejection, ${ }^{35}$ which show some similarities of the expression of MHC class II antigens.

Normally, VCAM-1 is absent on resting endothelial cells but, like ICAM-1, it can also be induced and upregulated rapidly during activation of the endothelial cells, which can also be the result of the induction of IL-1, INF- $\gamma$, TNF- $\beta$, and IL-4. ${ }^{14192136}$ Abnormal expression of VCAM-1 has been demonstrated in some inflammatory kidney diseases on the proximal tubular cells. ${ }^{37}$ The expression of ICAM-1 and VCAM-1 in diabetic epiretinal membranes demonstrated in the present study may also be due to the release and induction of inflammatory cytokines in the membranes shown by Tang and coworkers. ${ }^{7}$ In a small group of PDR cases Heidenkummer and Kampik also reported that ICAM-1 was found in nine out of 10 membranes..$^{38}$ Frequent and strong expression of ICAM-1 and VCAM-1 in epiretinal membranes of PDR implies that the primary cell to cell interactions among these cells, and between antigen presenting cells and lymphocytes, and the subsequent induction of immune responses could be one of the key factors in the complicated processes of the development of PDR.

Neovascularisation is one of the main pathological changes of proliferative diabetic retinopathy and may cause severe complications in patients. From previous reports we know very little about the significance of the neovascularisation, especially the vascular endothelial cells, in the development of PDR membranes. Here for the first time we demonstrate the extent of proliferation of the newly formed vessels and the activation of the vascular endothelial cells by detecting the expression of cell adhesion molecules (ICAM-1 and VCAM-1) on the endothelial cells in about $80 \%$ of the neovascularised epiretinal membranes of PDR. Interestingly, almost all of the vascular endothelial cells in the proliferating stage in the membranes were also in an activated state, although only a portion of the vessels were at the proliferating and activated stage. This provides strong evidence for the interaction of lymphocytes and endothelial cells, which has been considered to be the first critical step for lymphocyte migration into tissue and initiating an immune response, wherein ICAM-1 and VCAM-1 play the key role in these interactions. ${ }^{13299}$ The activation of vascular endothelial cells facilitates these processes. Besides, according to the observation in vitro, activation of vascular endothelial cells induced by cytokines (for example, IL-1, TNF, and IFN- $\gamma$ ) might lead to morphologic rearrangements of the cells and 
opening gaps between endothelial cells, ${ }^{40}{ }^{41}$ which further causes vascular leak syndrome. ${ }^{41}$ This may result in a series of events including the leakage of growth promoting factors enhancing tissue growth.

The proliferation state of the neovascular endothelial cells may reflect the proliferative activity of the epiretinal membranes of PDR and further the severity of the disease. It may also reflect the clinical course and prognosis of the disease. Our findings in this study thus give rise to the questions: when should PDR patients be operated (the opportunity of vitrectomy) - at an early stage or later? Is the proliferation state or activation of the endothelial cells a factor influencing the recurrent rate of vitreous haemorrhage and epiretinal membrane proliferation? Does inhibition of the endothelial cells, both their proliferation and their activation, influence the development of epiretinal membranes? The findings, therefore, give us hints towards pharmacological studies directly or indirectly on the inhibition of epiretinal membranes. However, all these aspects still need further investigation.

This work was presented at ARVO annual meeting 2-7 May 1993, Sarasota, Florida, USA

Part of the epiretinal membrane specimens used in this study were collected in the University Eye Hospital Munich, University of Munich, Germany. Tonsil tissues and human rejected kidney tissues were kindly offered respectively by the NET clinic and the Institute of Immunology, University of Munich, Germany. The authors would also like to thank Professor Dr F Hofstaedter, the Institute of Pathology, University of Regensburg, Germany for the use of the immunofluorescence microscope.

1 Clarkson JG, Green WR, Massof D. A histopathologic review of 168 cases of preretinal membrane. Am 7 Ophthalmol 1977; 84: 1-17.

2 Kampik A, Kenyon K, Michels R, Green WR, de la Cruz ZC. Epiretinal and vitreous membrane. A comparative study of 56 cases. Arch Ophthalmol 1981; 99: 1445-54

3 Hamilton CW, Chandler D, Klintworth GK, Machemer R. A transmission and scanning electron microscopic study of surgically excised preretinal membrane proliferations in diabetes mellitus. Am $\mathcal{F}$ Ophthalmol 1982; 94: 473-88.

4 Yamamoto T, Yamashita H, Horis S. Electron microscopic

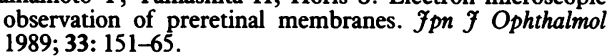

5 Scheiffarth OF, Kampik A, Günther H, von der Mark K. Proteins of the extracellular matrix in vitreoretinal membranes. Graefes Clin Exp Ophthalmol 1988; 226: 357-61.

6 Hui YH, Goodnight R, Zhang XJ, Sogente N, Ryan SJ. Glial epiretinal membranes and contraction. Immunohistochemical and morphological studies. Arch Ophthalmol 1988; 106: $1280-5$.

7 Tang S, Scheiffarth OF, Thurau SR, Wildner G. Cells of the immune system and their cytokines in epiretinal membranes and in the vitreous of patients with proliferative diabetic retinopathy (PDR). Ophthalmic Res 1993; 25: 177-85.

8 Baudouin C, Gordon WC, Fredj-Reygrobellet D, Baudouin F, Peyman G, Gastaud P, et al. Class II antigen expression in diabetic preretinal membranes. Am $\mathcal{F}$ Ophthalmol 1990; 109: $70-4$.

9 Weller M, Clausen R, Bresgen M, Heimann K, Wiedemann P. Immunoglobulin $\mathrm{G}$, complement factor $\mathrm{C} 3$ and lymphocytes in proliferative intraocular disorders. Int Ophthalmol 1990; 14: $277-83$

10 Heidenkummer HP, Kampik A. Vergleichende immunhistochemische Untersuchungen epiretinaler Membranen bei proliferativen vitreoretinalen Erkrankungen. (Comparative immunohistochemical investigations of epiretinal membranes in proliferative vitreoretinal disorders). Fortschr Ophthalmol 1991; 88: 219-24.

11 Dougherty GJ, Murdoch S, Hogg N. The function of human intercellular adhesion molecule-1 (ICAM-1) in the genera-

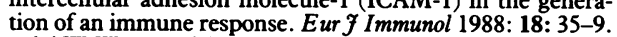

12 Boyd AW, Wawryk SO, Burns GF, Fecondo JV. Intercellular adhesion molecule 1 (ICAM-1) has a central role in cell-cell contact-mediated immune mechanisms. Proc Natl Acad Sci Contact-mediated immu

13 Dustin ML, Springer TA. Lymphocyte function-associated antigen-1 (LFA-1) interaction with intercellular adhesion molecule-1 (ICAM-1) is one of at least three mechanisms for lymphocyte adhesion to cultured endothelial cells. f Cell Biol 1988; 107: 321-31.

14 Carlos TM, Schwartz BR, Kovach NL, Yee E, Rosso M Osborn L, et al. Vascular cell adhesion molecule-1 mediates lymphocyte adherence to cytokine activated cultured human endothelial cells. Blood 1990; 76: 965-70.

15 Wallow IH, Geldner P. Endothelial fenestrate in proliferative diabetic retinopathy. Invest Ophthalmol Vis Sci 1980; 19: diabetic

16 Hagemeier H, Vollmer E, Goerdt S, Schulze-Osthoff K, Sorg C. A monoclonal antibody reacting with endothelial cells of budding vessels in tumors and inflammatory tissues, and non-reactive with normal adult tissues. Int $\mathcal{F}$ Cancer 1986 38: 481-8.

17 Joos KM, Sandra A. Microarterial synthetic graft repair: interstitial cellular components. Microsurgery 1990; 11: 268-77.

18 Rothlein R, Dustin ML, Marlin SD, Springer TA. A human intercellular adhesion molecule (ICAM-1) distinct from LFA-1. F Immunol 1986; 137: $1270-4$

19 Dustin ML, Rothleim R, Bhan AK,Dinarello CA, Springer TA. Induction by IL 1 and interferon- $\gamma$, tissue distribution, biochemistry, and function of a natural adherence molecule (ICAM-1). F Immunol 1986; 137: 245-54.

20 Simmons D, Makgoba MW, Seed B. ICAM, an adhesion ligand of LFA-1, is homologous to the neural cell adhesion molecule (NCAM). Nature (Lond) 1988; 331: 624-7.

21 Thornhill MH, Wellicome SM, Mahiouz DL, Lanchbury JSS, Kyan-Aung U, Harskard DO. TNF combines with IL-4 or IFN- $\gamma$ to selectively enhance endothelial cell adhesiveness for T cells: the contribution of VCAM- 1 dependent and independent binding mechanisms. F Immunol 1991; 146 592-8.

22 Sivaligam A, Kenney J, Brown GC, Benson WE, Donoso L. Basic fibroblast growth factor levels in the vitreous of patients with proliferative diabetic retinopathy. parch Ophthalmol 1990; 108: 869-72.

23 Schultz GS, Grant MB. Neovascular growth factors. Eye 1991; 5: $170-80$.

24 Wiedemann $P$. Growth factors in retinal diseases: proliferative vitreoretinopathy, proliferative diabetic retinopathy, and retinal degeneration. Surv Ophthalmol 1992; 36: 373-84.

25 Benson WE, Brown GC, Tasman W. Diabetes and its ocular complications. Philadelphia: Saunders, 1988: 24-6.

26 Melato M, Antonotto G, Manconi R, Poute E. Ocular deposits of immunoglobulin in diabetic retinopathy. $\mathrm{Can} \mathcal{F} \mathrm{Oph}$ thalmol 1982; 17: 45-6.

27 Jerdan JA, Michels RG, Glaser BM. Diabetic preretinal membranes. An immunohistochemical study. Arch Ophthalmol 1986; 104: 286-90.

28 Tang S, Scheiffarth OF. An immunohistochemical study of vitreal and epiretinal membranes in human eyes. vitreal and epiretinal membranes

29 Shimizu Y, Newman W, Tanaka Y, Shaw S. Lymphocyte interactions with endothelial cells. Immunol Today 1992; 13: 106-12.

30 Altmann DM, Hogg N, Trowsdale J, Wilkinson D. Cotransfusion of ICAM-1 and HLA-DR reconstitutes human antigen-presenting cell function in mouse $\mathrm{L}$ cells. Nature (Lond) $1989 ; 338: 512$

31 Graber N, Gopal TV, Wilson D, Beall LD, Polte T, Newman W. T cells bind to cytokine-activated endothelial cells via a novel, inducible sialoglycoprotein and endothelial leukocyte adhesion molecule-1. F Immunol 1990; 145: 819-30.

32 Elner SG, Elner VM, Pavilack MA, Todd RF, Mayo-Bond L Franklin WA, et al. Modulation and function of intercellular adhesion molecule-1 (CD54) on human retinal pigment adhesion molecule-1 (CD54) on human retin
epithelial cells. Lab Invest 1992; 66: 200-11.

33 Liversidge J, Sewell HF, Forrester JV. Interactions between lymphocytes and cells of the blood-retina barrier: mechanisms of $T$ lymphocyte adhesion to human retinal capillary endothelial cells and retinal pigment epithelial cells in vitro. Immunology 1990; 71: 390-6.

34 Konter U, Keller I, Kaufmann R, Mielke V, Sterry W. Adhesion molecule mapping in human skin. Arch Dermatol Res 1989; 281: 454-62.

35 Faull RJ, Russ GR. Tubular expression of intercellular adhesion molecule- 1 during renal allograft rejection. Transplantation 1989; 48: 226-30.

36 Osborn L, Hession C, Tizard R. Direct expression cloning of endothelial cell adhesion molecule-1 (VCAM-1), a cytokineinduced endothelial protein that binds to lymphocytes. Cell 1989; 59: 1203-11.

37 Seron D, Cameron JS, Haskard DO. Expression of VCAM-1 in normal and diseases kidney. Nephrol Dial Translplant $1991 ; 6: 917-22$

38 Heidenkummer HP, Kampik A. Intercellular adhesion molecule-1 (ICAM-1) and leukocyte function-associated antigen-1 (LFA-1) expression in human epiretinal mem-
branes. Graefes Arch Clin Exp Ophthalmol 1992; 230: 483-7.

39 Gallatin WM, Weissman IL, Butcher EC. A cell-surface molecule involved in organ-specific homing of lymphocytes. molecule involved in organ-specif
Nature (Lond) 1983; 304: 30-4.

40 Stolpen AH, Guinan EC, Fiers W, Poper JS. Recombinan tumor necrosis factor and immune interferon act singly and in combination to reorganize human vascular endothelial cell in combination to reorganize human vascula

41 Cotran RS, Pober JS, Gimbrone Jr MA, Springer TA, Wiebke $\mathrm{EA}, \mathrm{Gaspari} \mathrm{AA}$, et al. Endothelial activation during interleukin 2 immunotherapy. A possible mechanism for the vascular leak syndrome. F Immunol 1987; 139: 1883-8. 